Article

\title{
Enhanced Silver Nanoparticle Synthesis by Escherichia Coli Transformed with Candida Albicans Metallothionein Gene
}

\author{
Qunying Yuan ${ }^{1, * \mathbb{D}}$, Manjula Bomma ${ }^{1} \mathbb{D}$ and Zhigang Xiao ${ }^{2}$ \\ 1 Department of Biological and Environmental Science, Alabama A\&M University, Normal, AL 35762, USA; \\ mbomma@bulldogs.aamu.edu \\ 2 Department of Electrical Engineering and Computer Science, Alabama A\&M University, Normal, AL 35762, \\ USA; zhigang.xiao@aamu.edu \\ * Correspondence: qunying.yuan@aamu.edu; Tel.: +256-372-4241
}

Received: 16 August 2019; Accepted: 10 December 2019; Published: 12 December 2019

\begin{abstract}
In this study, the metallothionein gene of Candida albicans (C. albicans) was assembled by polymerase chain reaction (PCR), inserted into pUC19 vector, and further transformed into Escherichia coli (E. coli) DH5 $\alpha$ cells. The capacity of these recombinant $E$. coli DH5 $\alpha$ cells to synthesize silver nanoparticles was examined. Our results demonstrated that the expression of $C$. albicans metallothionein in E. coli promoted the bacterial tolerance to metal ions and increased yield of silver nanoparticle synthesis. The compositional and morphological analysis of the silver nanoparticles revealed that silver nanoparticles synthesized by the engineered E. coli cells are around $20 \mathrm{~nm}$ in size, and spherical in shape. Importantly, the silver nanoparticles produced by the engineered cells were more homogeneous in shape and size than those produced by bacteria lack of the C. albicans metallothionein. Our study provided preliminary information for further development of the engineered E. coli as a platform for large-scale production of uniform nanoparticles for various applications in nanotechnology.
\end{abstract}

Keywords: biosynthesis; silver nanoparticles; engineered Escherichia coli; metallothionein

\section{Introduction}

Nanoparticles (NPs) have been explored for a wide range of applications, including biosensors and chemical sensors, bioimaging, catalysis, optics, electronics, drug delivery, and energy [1]. The conventional chemical or physical methods for the production of nanoscale materials depend on the utilization of toxic stabilizing and capping agents, which pose risks to the environment and human health [2]. Therefore, there is an increasing need to develop cost-effective, non-toxic, and environmentally green approaches that do not use toxic chemicals to produce NPs. The microbial synthesis of NPs, which takes advantage of microbial detoxification of metallic ions and precipitation of metals through reducing enzymes, intracellular or extracellular reducing reagents and metal-binding proteins, showed immense potential [3,4].

In particular, there is an increasing interest in the exploitation of the cysteine-rich metal-binding proteins, metallothioneins (MTs), in the development of biofactories for metal NP production. MTs are found in all eukaryotes, as well as some prokaryotes, and play an important role in intracellular metal distribution, accumulation, as well as protection of cells against heavy metal toxicity and oxidative stress [5,6]. The Cys-Xaa-Cys clusters of MTs can act as a reducing functional group for the reduction of metal ions, chelation, and accumulation of metal particles in the cells [5-7]. Studies showed that MTs are involved in the detoxification of several metals, including zinc, mercury, copper and cadmium in microorganisms $[5,6,8]$. Due to their important role in metal reduction and high metal binding affinity, 
studies have been seeking to integrate MTs in creating biological platforms for the production of metal NPs. Engineered bacteria expressing MT and/or phytochelatins have been shown to be able to produce diverse nanoparticles [9-11].

A critical aspect in developing a microbial platform for NP synthesis is choosing a proper host microorganism. It is ideal that a biofactory can make NPs with consistent properties for their applications in various field of nanotechnology. Many types of microorganism have been shown to be able to synthesize various metal NPs, but with diverse properties [12-16]. In addition, the conditions for cultivation and maintenance of microorganisms vary for different species [14-16]. Among the microorganisms able to serve as potential biofactories for metal NP synthesis, the readily available bacteria, E. coli, is of particular interest, due to the relatively easy and simple procedures to grow, maintain and manipulate them in the lab. The potential of engineered E. coli as a common platform for synthesis of diverse NP has been explored; however, the efficiency of NP synthesis by the engineered bacteria and the potential to upgrade to large scale NP production were not examined [9-11].

The goal of this study was to provide preliminary evidence for exploiting engineered E. coil as a platform for the large-scale production of metal NPs with controlled morphological properties. In this study, we chose C. albicans MT as a target protein and transferred a PCR-assembled C. albicans MT gene into $E$. coli $\mathrm{DH} 5 \alpha$ cells to examine whether expression of $C$. albicans MT in E. coli would improve bacterial NP synthesis.

Compared to E. coli MT, which has four cysteine out of 56 residues (7.1\%), the C. albicans MT has a relatively high content of cysteine residues (15.8\%). Importantly, the C. albicans has four repeats of Cys-Xaa-Cys presumably for binding metal ions, such as copper $[17,18]$. To examine whether the expression of this MT protein will improve NP synthesis, we used biosynthesis of silver NPs as an example to investigate the effects of C. albicans MT on NP production. Our results showed that the E. coli cells expressing C. albicans MT produced silver NPs faster than E. coli cells transformed with pUC19 empty vectors. Particularly, the silver NPs synthesized by engineered E. coli are more uniform in size and shape.

\section{Materials and Methods}

\subsection{Synthesis of C. Albicans MT Gene and Transformation of E. Coli DH5 $\alpha$ Cells}

To obtain the C. albicans MT gene, first, the MT protein sequence of the $C$. albicans was obtained from the NCBI protein database. Then the C. albicans MT gene was codon-optimized for protein expression in E. coli, and eight oligonucleotides for gene synthesis were designed using DNAworks. The oligonucleotides were synthesized by Eurofins Genomics (Louisville, KY, USA). The C. albicans gene was synthesized in four consecutive PCR reactions, as described by D. Marsc [19]. Assembled gene was inserted between HindIII and BamHI sites of plasmid pUC19 through in vivo homologous recombination in E. coli $\mathrm{DH} 5 \alpha$ cells. Plasmids were propagated in E. coli $\mathrm{DH} 5 \alpha$ cells, and clones carrying the error-free gene are confirmed by DNA sequencing (Eurofins Genomics, Louisville, KY, USA). To obtain genetically modified E. coli cells for NP synthesis, a single colony of E. coli DH5 $\alpha$ cells transformed with the sequence-verified plasmid was inoculated in $5 \mathrm{~mL}$ of Luria-Bertani (LB) medium in the presence of $100 \mu \mathrm{g} / \mathrm{mL}$ of carbenicillin and cultured overnight at $37^{\circ} \mathrm{C}$ with a continuous shake at $250 \mathrm{rpm}$. The overnight culture was centrifuged using Sorvall Legend X1R (Fisher Scientific, Pittsburgh, PA, USA) and the cell pellet was resuspended in $15 \mathrm{~mL}$ of fresh LB medium containing $100 \mu \mathrm{g} / \mathrm{mL}$ of carbenicillin. The cells were further cultured at $37^{\circ} \mathrm{C}$ with a continuous shake for 30-45 min. Then glycerol was added to the cells to reach a final concentration of $15 \%$ and cells were stored at $-80{ }^{\circ} \mathrm{C}$ for future use. All chemicals and reagents were purchased from Fisher Scientific (Pittsburgh, PA, USA) unless specified. 


\subsection{Monitoring Cell Growth}

To examine whether the expression of $C$. albicans MT in E. coli affects cell growth, we monitored cell growth along time of cultivation. $50 \mu \mathrm{L}$ of the glycerol stock cells containing the $C$. albicans MT gene inserted in pUC19 plasmid (pUC-Met) was inoculated in $10 \mathrm{~mL}$ of LB in the presence of $100 \mu \mathrm{g} / \mathrm{mL}$ carbenicillin and cultured overnight at $37{ }^{\circ} \mathrm{C}$ in a shaker incubator. Cells were spun down and resuspended in $100 \mathrm{~mL}$ of $\mathrm{LB}$ with $100 \mu \mathrm{g} / \mathrm{mL}$ carbenicillin. Optical density at $600 \mathrm{~nm}\left(\mathrm{OD}_{600 \mathrm{~nm}}\right)$ was monitored each hour after resuspension until $\mathrm{OD}_{600 \mathrm{~nm}}$ reached between 0.6 and 0.8 , then $\mathrm{OD}_{600 \mathrm{~nm}}$ was measured at $24 \mathrm{~h}, 48 \mathrm{~h}$ and $72 \mathrm{~h}$. It has been shown that MT expression was induced and upregulated when microorganisms are under heavy metal stress $[5,6,17,18]$. To further investigate whether the expression of C. albicans MT in E. coli impact the bacterial tolerance to heavy metal, we cultivated the bacteria in the presence of $0.2 \mathrm{mM} \mathrm{CuSO}_{4} .0 .2 \mathrm{mM}$ of $\mathrm{CuSO}_{4}$ was added to the cells after $\mathrm{OD}_{600 \mathrm{~nm}}$ reached between 0.6 and 0.8 . Cells were further cultivated at $37^{\circ} \mathrm{C}$ for $17-19 \mathrm{~h}$ with a continuous shake. $\mathrm{OD}_{600 \mathrm{~nm}}$ was measured again before cells were collected by centrifugation at $4000 \times g$ for $10 \mathrm{~min}$. E. coli cells transformed with pUC19 empty vector (pUC19-Vec) was used as control.

The viability of the cells after they grew overnight in the presence of $0.2 \mathrm{mM} \mathrm{CuSO}_{4}$ was estimated by plating the cells from the overnight culture on agar plates. The overnight bacterial culture was diluted with LB medium at a ratio of 1:1000, 1:10,000, 1:100,000 and 1:1,000,000, and $100 \mu \mathrm{L}$ of each dilution was plated on agar plates in the absence of $\mathrm{CuSO}_{4}$. Cells were allowed to grow overnight at $37^{\circ} \mathrm{C}$ for $17 \mathrm{~h}$ to obtain colonies. Individual colonies were counted to estimate the viable cells after $\mathrm{CuSO}_{4}$ challenge.

\subsection{Determination of MT Protein Expression}

C. albicans MT was identified as a copper binding protein, and its level increases under metal ion stresses $[5,6,17,18]$. To analyze the expression level of $C$. albicans MT in E. coli, the preparation of overnight culture for examining protein expression was carried out similarly as described in "Monitoring Cell Growth". The overnight cell culture was centrifuged, and cells were resuspended in $100 \mathrm{~mL}$ of $\mathrm{LB}$ containing carbenicillin and grown at $37^{\circ} \mathrm{C}$. When $\mathrm{OD}_{600 \mathrm{~nm}}$ reached between 0.6 and 0.8 , bacteria were grown for another $8 \mathrm{~h}$ for MT protein expression analysis. Cell pellets were resuspended in lysis buffer containing $50 \mathrm{mM}$ Tris- $\mathrm{HCl}, \mathrm{pH} 8,50 \mathrm{mM} \mathrm{NaCl}$ at a ratio of about $0.05 \mathrm{~g}$ wet cells $/ \mathrm{mL}$ of buffer and sonicated to break apart the cells. The whole lysate was centrifuge again at $15,000 \times g$ for $30 \mathrm{~min}$ to separate the soluble proteins from the cell membrane debris. Soluble proteins were passed through a GE Healthcare Vivaspin ${ }^{\mathrm{TM}}$ concentrator with a 30-kDa cutoff to remove the proteins larger than $30 \mathrm{kDa}$. Subsequently, the flow through was further concentrated with GE Healthcare Vivaspin $^{\mathrm{TM}}$ concentrator with a 3-kDa cutoff. 10, 20, $40 \mu \mathrm{g}$ of the concentrated proteins smaller than 30 $\mathrm{kDa}$ were run on $16 \% \mathrm{~T}, 4 \% \mathrm{C}$ Tricine SDS-PAGE gel to separate the proteins. Proteins were stained in buffer containing 30\% methanol, 10\% glacial acetic acid, $0.1 \%$ Coomassie blue and $60 \%$ water for at least $2 \mathrm{~h}$. Then the gel was destained in the same buffer without Coomassie blue, for overnight with continuous shake. Gel picture was taken using Gel Doc EZ Gel Documentation System (Biorad, Hercules, CA, USA).

\subsection{Biosynthesis of Silver NPs by Bacteria}

The preparation of overnight culture for silver NP synthesis was carried out similarly as described in "Monitoring Cell Growth". The overnight cell culture was centrifuged, and cells were resuspended in $100 \mathrm{~mL}$ of $\mathrm{LB}$ in the presence of carbenicillin and grown at $37^{\circ} \mathrm{C} . \mathrm{AgNO}_{3}$ was added to the culture when $\mathrm{OD}_{600 \mathrm{~nm}}$ reached between $0.6-0.8$. Cells were further cultured at $37^{\circ} \mathrm{C}$ with continuous shaking for $72 \mathrm{~h}$. Samples were taken to measure $\mathrm{OD}_{600 \mathrm{~nm}}$ at $24 \mathrm{~h}, 48 \mathrm{~h}$ and $72 \mathrm{~h}$ after addition of $\mathrm{AgNO}_{3}$. To estimate the yield of silver NPs in a larger scale, we carried out three experiments in which bacteria were grown in $1 \mathrm{~L} \mathrm{LB}$ medium in the presence of $1 \mathrm{mM} \mathrm{AgNO}_{3}$ under the same conditions as for small scales. The wet weight of pellet collected after $72 \mathrm{~h}$ of cultivation was measured. After each $\mathrm{OD}_{600 \mathrm{~nm}}$ 
measurement, cultures sat for $30 \mathrm{~min}$ to allow particles to settle down on the bottom of the flask and take pictures of the precipitates. pUC19-Vec cells were used as a control in this experiment.

\subsection{Collection of NPs}

After $72 \mathrm{~h}$ of cultivation, cell culture was centrifuged at $4000 \times \mathrm{g}$ for $10 \mathrm{~min}$. The cell pellets were resuspended in $1.5 \mathrm{~mL}$ of $4 \mathrm{M}$ urea, sonicated for three cycles of $45 \mathrm{~s}$ at an output of $20 \%$, with an interval of 1 min between each cycle (Sonic Dismembrator, Model 50; Fisher Scientific, Pittsburgh, PA, USA). The lysate was then transferred to a $2-\mathrm{mL}$ microcentrifuge tube and further spun at $10,000 \times g$ for $10 \mathrm{~min}$ (accuSpin ${ }^{\mathrm{TM}}$ Microcentrifuge, Fisher Scientific, Pittsburgh, PA, USA). The supernatant was discarded, and the pellet was resuspended in $1 \mathrm{~mL}$ of $4 \mathrm{M}$ urea by 3-4 pulses of sonication, followed by centrifugation to remove the supernatant. The pellet was further washed twice with $1 \mathrm{~mL}$ of sterile deionized water. The final pellet was resuspended in sterile deionized water and stored in the dark at $4{ }^{\circ} \mathrm{C}$ for next step characterizations.

\subsection{Fourier Transform Infrared (FTIR) Spectral Analysis}

FTIR was used to reveal the functional groups that may be responsible for reducing and stabilizing the bioreduced silver NPs. The isolated NPs were diluted in deionized water, and The FTIR spectra were collected at a resolution of $2 \mathrm{~cm}^{-1}$ in transmission mode range between 4000 and $500 \mathrm{~cm}^{-1}$ using NICOLET IS10 FTIR (ThermoFisher, Waltham, MA, USA). Sterile deionized water was used as blank for this experiment.

\subsection{Scanning Electron Microscopic and Scanning Transmission Electron Microscopic Characterization}

We used scanning electron microscopy (SEM) and scanning transmission electron microscopy (STEM) to determine the morphological properties of the biologically synthesized silver NPs. The samples for SEM and TEM were prepared similarly. NPs washed with urea and deionized water were resuspended in sterile deionized water.

An FEI Tecnai F30 super-twin field-emission-gun transmission electron microscope (TEM) (manufactured by the FEI Company in Hillsboro, OR, USA) operating at $300 \mathrm{kV}$ was used to acquire the TEM images, electron diffraction patterns and annular dark-field (ADF) scanning transmission electron microscopy (STEM) images. Chemical composition was explored using an X-ray energy dispersive spectrometer (EDS) attached to the TEM. A dual-beam focus ion beam (FIB) (FEI Helios 600 dual-beam FIB) was used to obtain the SEM images of the biosynthesized silver NPs. The size of NPs was analyzed using Gatan Digital Micrograph Software.

\subsection{Statistical Analysis}

All data are expressed as mean \pm SD. Comparison between groups was evaluated with the Student t-test. Probability values of $<0.05$ were considered significant.

\section{Results}

\subsection{MT Gene Assembly in vitro and Expression of MT in E. coli DH5 $\alpha$ Cells}

We synthesize the $C$. albicans MT gene instead of cloning it from the C. albicans' genome for two reasons. First, we could obtain the gene without the need of C. albicans' genomic DNA; second, it allowed us to optimize codons for improving the expression of a yeast protein in E. coli. Eight oligonucleotides covering the full length of $C$. albicans MT gene were designed to synthesize the gene by PCR followed the procedure described in reference 19. The full length of C. albicans MT gene was assembled in four consecutive PCR reactions (Figure 1A,B). The expected length of the final PCR product is 288 base pairs the product of each PCR reaction was run on a $1 \%$ agarose gel. The incremental increase in DNA size indicated the successful assembly of the gene (Figure 1B). 
The full-length C. albicans MT protein has 76 residues with a calculated molecular weight of $7.8 \mathrm{kDa}$, and has $15.8 \%$ (12/76) cysteine residues (Figure 1C).

A

ATGGCGTGCTCTGCGGTTCAGTGTGTTTGTGCGCAGAAATCT ACCTGCTCTTGCGGTAAACAGCCGGCACTGAAATGCAACTGC TCTAAAGCGTCTGTTGAAAACGTTGTTCCGTCTTCTAACGAC GCGTGTGCGTGCGGCAAACGTAACAAATCTTCTTGCACCTGC GGTGCGAACGCGATCTGCGACGGTACGCGTGACGGTGAAAC CGACTTCACCAACCTGAAATAA

\section{C}

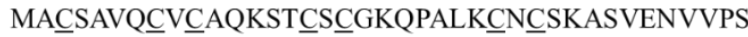
SNDACAㄷGKRNKSSㅁTㅁGANAICDGTRDGETDFTNLK

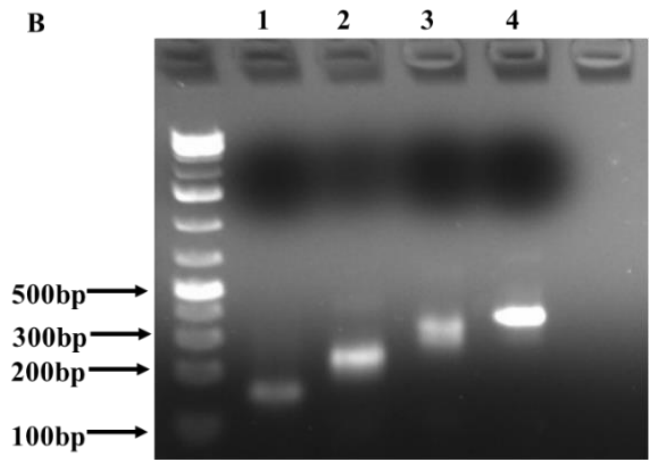

Figure 1. Gene assembly of Candida albicans metallothionein gene. (A): The nucleotide sequence of C. albicans metallothionein (GenBank: KHC50670.1). The percentage of cysteine residues (underscored) in the full peptide is $\sim 15.8 \%$. Its calculated molecular weight is $7.8 \mathrm{Kd}$; $(\mathbf{B})$ : PCR-based synthesis of the C. albicans metallothionein gene; (C): The peptide sequence of $C$. albicans metallothionein.

16\% T, 4\% C Tricine SDS-PAGE and Coomassie blue staining were used to analyze the expression of C. albicans MT protein in E. coli. Figure 2. showed the intensity of a band with a size between 5-10 kDa was enhanced in the proteins smaller than $30 \mathrm{kDa}$ from pUC-Met cells (arrow pointed). The size of this band in pUC-Met cells matched the predicted molecular weight of the C. albicans MT protein; while the band with a similar size was much weaker in pUC19-Vec cells. It is possible that the C. albicans MT was co-localized with an endogenous protein. In addition, the insertion of the C. albicans metallothionein gene between BamHI and HindIII of pUC19 added a few more residues to the original peptide and increased its molecular weight to $\sim 8.5 \mathrm{kDa}$. We believe that the increase in the intensity of this band was due to the expression of the recombinant C. albicans MT.

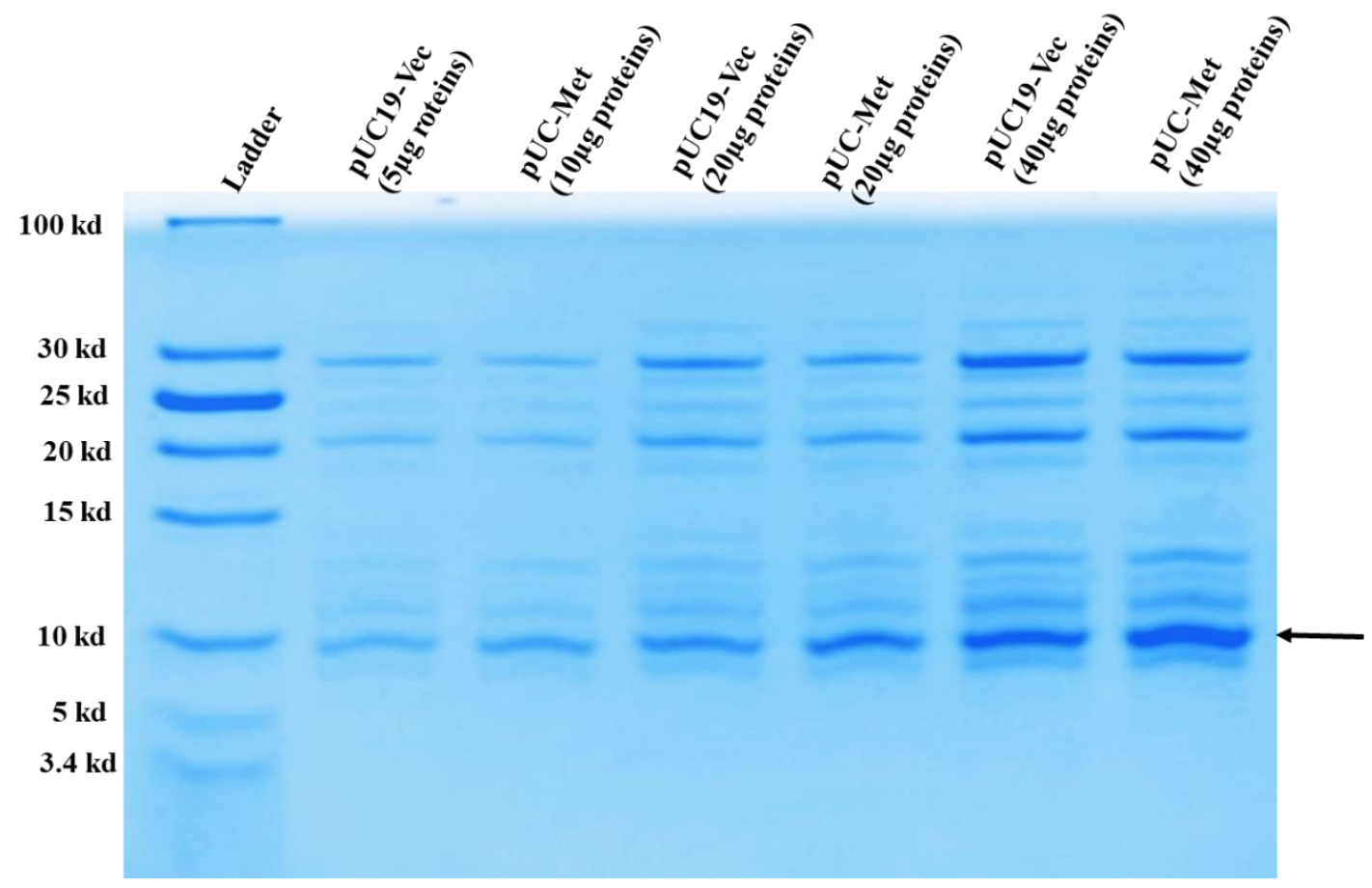

Figure 2. Expression of C. albicans metallothionein. 10, 20, $40 \mu \mathrm{g}$ of soluble proteins smaller than $30 \mathrm{kDa}$ from pUC19-Vec and pUC-Met group were run on 16\% T, 4\% C Tricine SDS-PAGE gel and stained with Coomassie blue. 


\subsection{Cell Growth and Survival during Extended Cultivation and Copper Ion Challenge}

Once we revealed that the C. albicans MT protein was expressed in E. coli, we continue to explore whether its expression can facilitate bacterial growth, as well as metal NP biosynthesis. Our results supported the notion that the expression of C. albicans MT protein promoted bacterial growth and survival. Under the same cultivation conditions, it appeared that the engineered recombinant pUC-Met cells grew faster and survived better than the pUC19-Vec cells during extended cultivation. We chose $\mathrm{OD}_{600 \mathrm{~nm}}$ between 0.6 and 0.8 as the baseline for monitoring growth rate, because this $\mathrm{OD}_{600 \mathrm{~nm}}$ range usually indicates the bacteria are at their fastest-growing stage and an inducer is added to induce protein expression if the target gene is under the control of an inducible promoter. When the starter culture was similar, at the point when $\mathrm{OD}_{600 \mathrm{~nm}}$ of pUC19-Vec cells reached between 0.5 and $0.6(0.59 \pm 0.044, \mathrm{n}=7)$, the $\mathrm{OD}_{600 \mathrm{~nm}}$ of pUC-Met cells was between 0.6 and $0.8(0.68 \pm 0.097, \mathrm{n}=7)$ (Figure $\left.3 \mathrm{~A}, \mathrm{~B}\right)$. At $24 \mathrm{~h}$ after $\mathrm{OD}_{600 \mathrm{~nm}}$ reached between 0.6 and 0.8 , the $\mathrm{OD}_{600 \mathrm{~nm}}$ measurement of engineered pUC-Met cells was significantly higher than that of pUC19-Vec cells (Figure 3A. OD $600 \mathrm{~nm}: 1.33 \pm 0.15$ vs. $1.47 \pm 0.12$; $p<0.05, \mathrm{n}=7$ ). Similar trends were observed at $48,72 \mathrm{~h}$ of cultivation, even if the measurements were not significantly different (Figure 3A). Furthermore, the pUC-Met cells performed better than the pUC19-Vec cells when the cells grew $17-19 \mathrm{~h}$ in the presence of $0.2 \mathrm{mM} \mathrm{CuSO}_{4}$. The growth of pUC-Vec cells was significantly slowed down, compared to the pUC-Met cells (Figure 3B. OD $600 \mathrm{~nm}: 1.11 \pm 0.21$ vs. $1.61 \pm 0.008, \mathrm{n}=3, p<0.05)$. These results suggested that the expression of $C$. albicans MT helped cell grow and survive during extended cultivation and under heavy metal challenge. To determine that the higher $\mathrm{OD}_{600 \mathrm{~nm}}$ was due to higher survival of pUC-Met cells under stress, we plated the bacteria on agar plates in a serial of dilution after they were exposed to $0.2 \mathrm{mM} \mathrm{CuSO}_{4}$ for $17-19 \mathrm{~h}$. Results of 1:1000 and 1:10,000 dilution were not shown because there were too many colonies, and it was not easy to count the individual colonies. Results of 1:100,000 and 1:1,000,000 dilutions were shown in Figure 3C. We found that that the pUC-Met cells after overnight cultivation in medium containing $\mathrm{CuSO}_{4}$, not only gave rise to more colonies, but also these colonies were larger than the ones from pUC19-Vec cells (Figure 3C). The estimated viable cell number after overnight $\mathrm{CuSO}_{4}$ challenge was $6.4 \times 10^{8}$ in the pUC-Met group, while it was $2.4 \times 10^{8}$ in pUC19-Vec group. Thus, we demonstrated that the expression of $C$. albicans MT increased the tolerance of recombinant $E$. coli to copper ion and facilitated cell survival under heavy metal stress.

\subsection{Yield of Silver NPS}

After we found that expression of C. albicans MT helped bacteria grow and improved their resistance to metal ions, we went on to examine whether this would allow the bacteria to produce NPs with improved yield and quality. A color change in the medium after addition of $\mathrm{AgNO}_{3}$ to the bacteria culture is usually a sign of NP formation. We not only observed a color change from yellow to brown, but also detected a large amount of black precipitates in all groups of cells. Pictures of precipitates at the bottom of the flasks were taken after culture containers sat at room temperature for $30 \mathrm{~min}$. We observed more dark precipitates formed by pUC-Met cells (Figure 4A-D) at 24 and $72 \mathrm{~h}$ after addition of $\mathrm{AgNO}_{3}$. Importantly, the wet weight of pellets obtained after centrifugation of $1 \mathrm{~L}$ bacterial culture was greater than that of pUC19-Vec cells $(0.89 \pm 0.04 \mathrm{~g} / \mathrm{L}$ in pUC19-Vec vs. $1.55 \pm 0.084 \mathrm{~g} / \mathrm{L}$ in $\mathrm{pUC}-\mathrm{Met} . \mathrm{N}=3 . p<0.05$ ) (Figure $4 \mathrm{~F})$. Thus, our data suggested that the expression of MT facilitated cell survival, as well as the yield of NP production. 

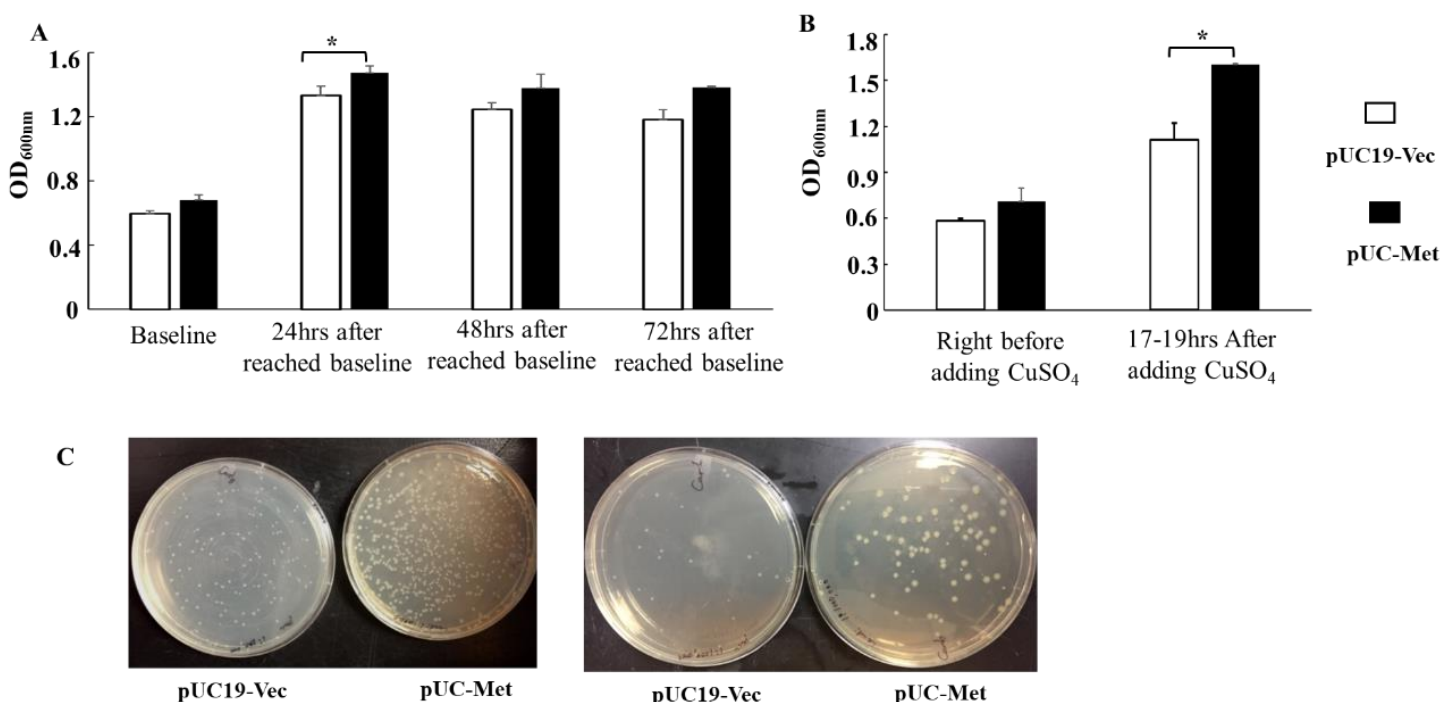

Figure 3. Bacterial cell growth during extended cultivation and upon $\mathrm{CuSO}_{4}$ challenge. (A): $\mathrm{D}_{600 \mathrm{~nm}}$ measurements of bacteria culture at different time points during 72-h cultivation in the absence of metal ions. The baseline measurement was taken when the $\mathrm{OD}_{600 \mathrm{~nm}}$ of $\mathrm{pUC19}-\mathrm{Vec}$ bacterial culture reached around 0.6 ( $\mathrm{n}=7$ for baseline and 24-h groups, ${ }^{*}: p<0.05 . \mathrm{n}=3$ for 48-h and 72-h groups); (B): $\mathrm{OD}_{600 \mathrm{~nm}}$ measurements of bacteria culture before and 17-19 $\mathrm{h}$ after adding $0.2 \mathrm{mM} \mathrm{CuSO}_{4}(\mathrm{n}=4$, *: $p<0.05)$; (C): Cell viability after $0.2 \mathrm{mM} \mathrm{CuSO}_{4}$ challenge. The cells after $17 \mathrm{~h}$ of cultivation in LB containing $0.2 \mathrm{mM} \mathrm{CuSO}_{4}$ were plated on agar plates at 1: 100,000 dilution (left panel) and 1:1,000,000 dilution (right panel), and further incubated overnight at $37^{\circ} \mathrm{C}$.

A

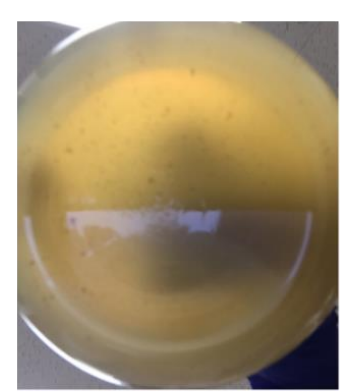

$\mathbf{E}$
B

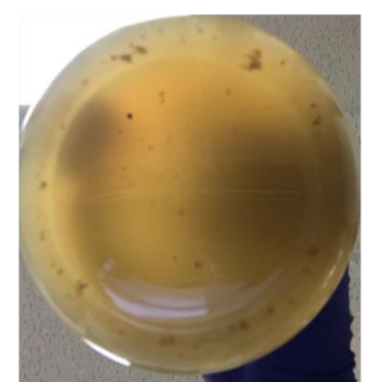

C

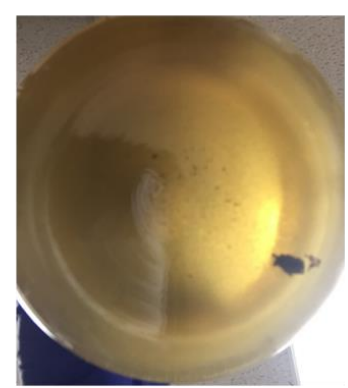

F
D
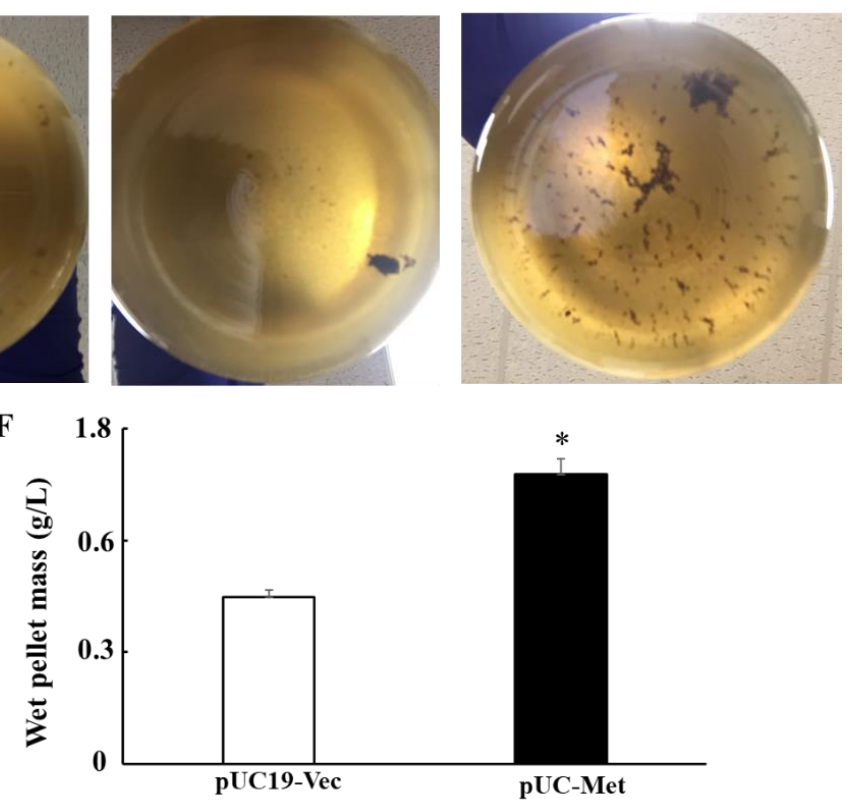

Figure 4. Silver nanoparticle yield of bacteria. Representative pictures were taken after culture sat for $30 \mathrm{~min}$ to allow the precipitates to settle down. (A,B): pUC19-Vec cells (A) and pUC-Met cells (B) $24 \mathrm{~h}$ after addition of $1 \mathrm{mM} \mathrm{AgNO}$; (C,D): pUC19-Vec cells (C) and pUC-Met cells (D) $72 \mathrm{~h}$ after addition of $1 \mathrm{mM} \mathrm{AgNO}$; (E): Pellets collected after $72 \mathrm{~h}$ of cultivation in $100 \mathrm{~mL}$ medium containing $1 \mathrm{mM}$ $\mathrm{AgNO}_{3}$. Left tube: From pUC19-Vec cells; right tube: From pUC-Met cells; (F): Quantitation of wet weight of pellets from $1 \mathrm{~L}$ bacteria culture in the presence of $1 \mathrm{mM} \mathrm{AgNO}_{3}$. ${ }^{*}: p<0.05, \mathrm{n}=3$. 


\subsection{Identification of the Functional Groups Involved in Reducing and Stabilizing Silver NPS}

The mechanisms of bacterial biological synthesis of metal NPs involve the presence of metal-binding protein peptides, reducing enzymes and functional groups that can donate electrons in the bacteria $[4,7,12,13,20-22]$. FTIR is able to identify the chemical composition of biological samples. We used FTIR to analyze the possible reducing functional groups in the bacteria that are involved in reducing and stabilizing silver ions. Three peaks were identified in the silver NP samples around $1640 \mathrm{~cm}^{-1}, 2080 \mathrm{~cm}^{-1}$ and $3440 \mathrm{~cm}^{-1}$. The sharp, strong peak at $1640 \mathrm{~cm}^{-1}$ was probably the stretch of amide I bonds $(\mathrm{C}=\mathrm{O})$, from the conversion of $\mathrm{C}-\mathrm{OH}$ biomolecules. The absorption peak at $1640 \mathrm{~cm}^{-1}$ shows that proteins are interacting with biosynthesized nanoparticles, and also their secondary structure were not affected during reaction with $\mathrm{Ag}^{+}$ions or after binding with silver NPs $[23,24]$, while the peak at around $2090 \mathrm{~cm}^{-1}$ was likely the stretch of isothiocyanate group $(\mathrm{N}=\mathrm{C}=\mathrm{S})$. The broad strong stretch of compounds, ranging from $3200 \mathrm{~cm}^{-1}$ to $3600 \mathrm{~cm}^{-1}$, were assigned to both phenols $(\mathrm{O}-\mathrm{H})$ and amines $(\mathrm{N}-\mathrm{H})$ (Figure 5). These results were generally similar to what has been reported with the exception of isothiocyanate compounds $[23,24]$. There were no differences in the peaks between the two groups of cells, suggesting that the bacteria probably used similar functional groups in the reduction of metal ions and the formation of NPs.

A

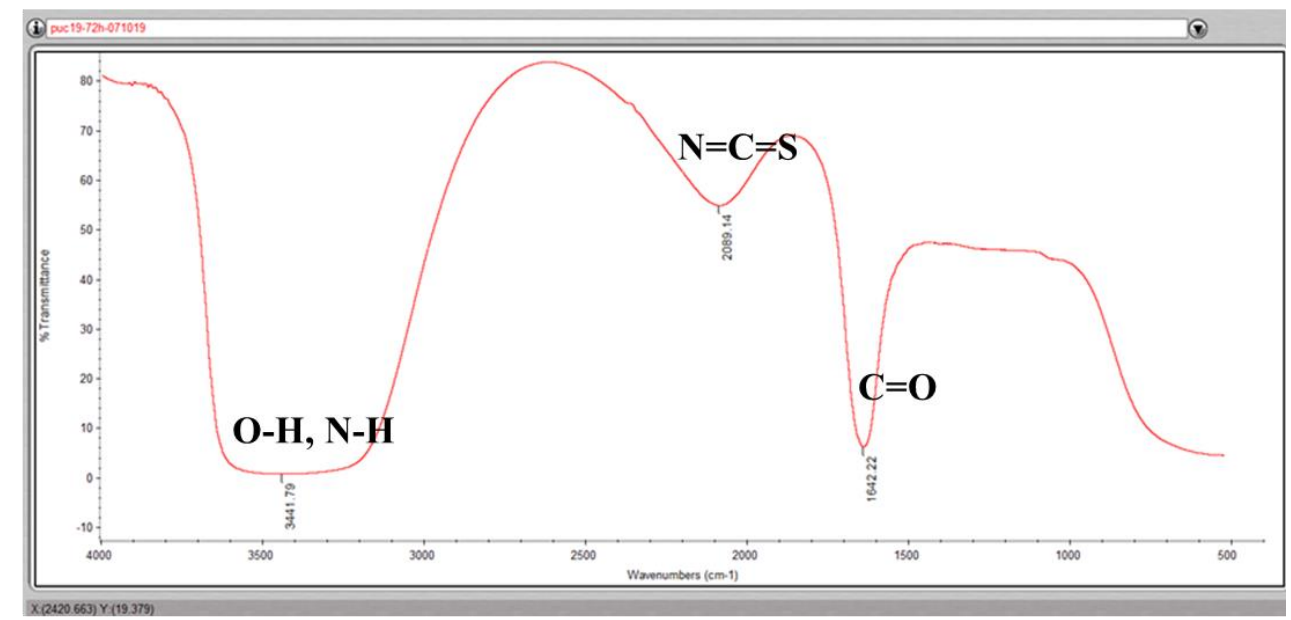

B

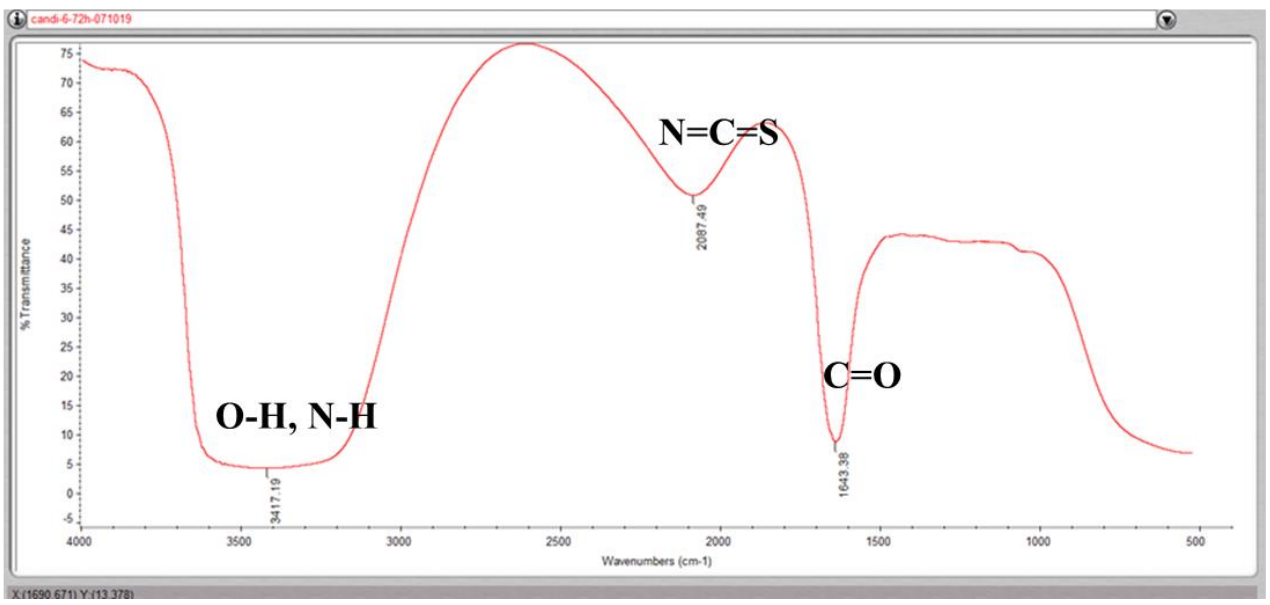

Figure 5. FTIR spectra scanning of silver nanoparticles (NPs). (A): FTIR spectra of NPs produced by pUC19-Vec cells; (B): FTIR spectra of NPs produced by pUC19-Met cells. In both groups, four potential functional groups were observed: Phenol $(\mathrm{O}-\mathrm{H})$, amine $(\mathrm{N}-\mathrm{H})$, isothiocyanate $(\mathrm{N}=\mathrm{C}=\mathrm{S})$ and amide I $(\mathrm{C}=\mathrm{O})$. 


\subsection{Characterization of Silver NPs Using Scanning Electron Microscopy and Scanning Transmission Electron Microscopy}

To confirm that bacteria did produce silver NPs, and to determine the compositions and morphological properties of the NPs, we examined the NPs using EDS, SEM and Scanning TEM.

$X$-ray EDS compositional analysis identified that the major element in the particles was silver (Figure 6), confirming that the bacteria indeed synthesized silver NPs. Other elements found in the NPs included chloride, sulfur and copper (Figure 6). The detection of sulfur was particularly interesting, since it showed that the thiol groups of cysteine residues were in fact involved in reducing silver ions. Importantly, the analysis of the particle images also proved that all E. coli cells produced silver particles in the nano-size range (Figures 7 and 8). The silver NP images in Figure 8 were selected for size analysis using Gatan Digital Micrograph Software. Figure 8 showed that the size of NPs produced by pUC19-Vec cells was slightly and significantly larger (Figure 8F,G. pUC19-Vec: $23.9 \pm 7.3 \mathrm{~nm}$. $\mathrm{n}=40$; pUC-Met: $20.0 \pm 3.7 \mathrm{~nm}, \mathrm{n}=49 . p<0.05$ ). Our results suggested that the NPs synthesized by pUC-Met cells were more homogeneous. Firstly, the size of the NPs formed by pUC-Met cells was more homogeneous, which was demonstrated by the difference in the standard deviation (SD) of the NP size. The SD of the size of NPs (not including the large crystals shown in Figure 8C) made by pUC19-Vec cells (SD $=7.3 \mathrm{~nm}$ ) was much greater than that produced by pUC-Met cells $(\mathrm{SD}=3.7 \mathrm{~nm})$. Furthermore, the NPs produced by pUC-Met cells mostly had a round spherical shape (Figures 7B and $8 \mathrm{D}, \mathrm{E}$ ); while the NPs synthesized by pUC19-Vec cells were more diverse (Figures 7A and 8A-C). The heterogeneity of the NPs synthesized by the pUC19-Vec cells was further exemplified by the presence of some micro-size silver crystals with shapes of cube, rectangular and hexagonal prism (Figure 8C). Thus, the results of SEM and STEM examination demonstrated that the engineered cells synthesized more uniform silver NPs in both size and shape.

A

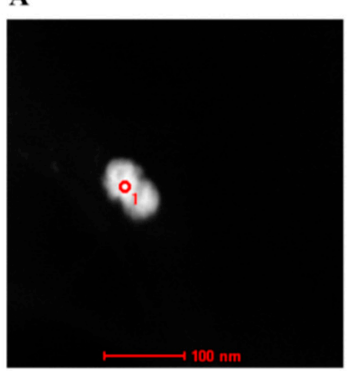

C

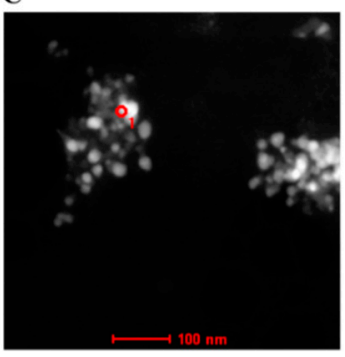

B



D

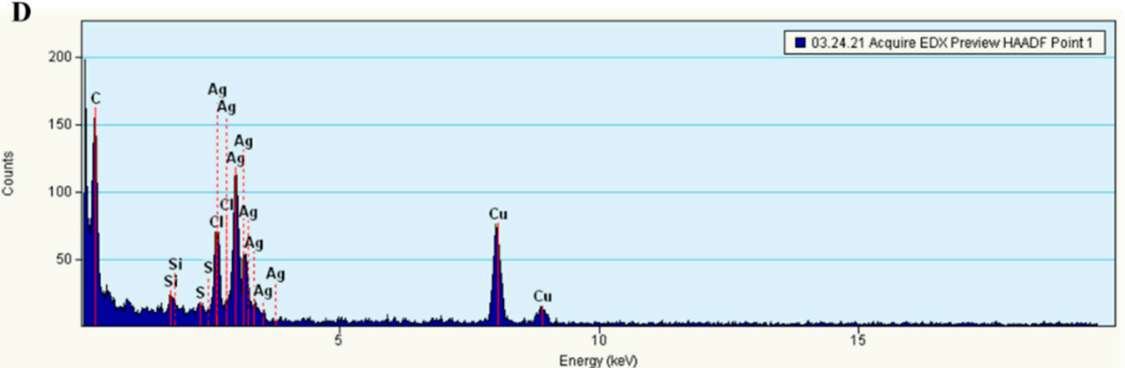

Figure 6. STEM compositional analysis of NPs. (A): A representative NP synthesized by pUC19-Vec cells was chosen for compositional analysis; (B): Elements in the NP in Figure A detected by STEM; (C): A representative NP synthesized by pUC19-Met cells was chosen for compositional analysis;

(D): Elements detected by STEM in NPs synthesized by pUC-Met cells. 
A

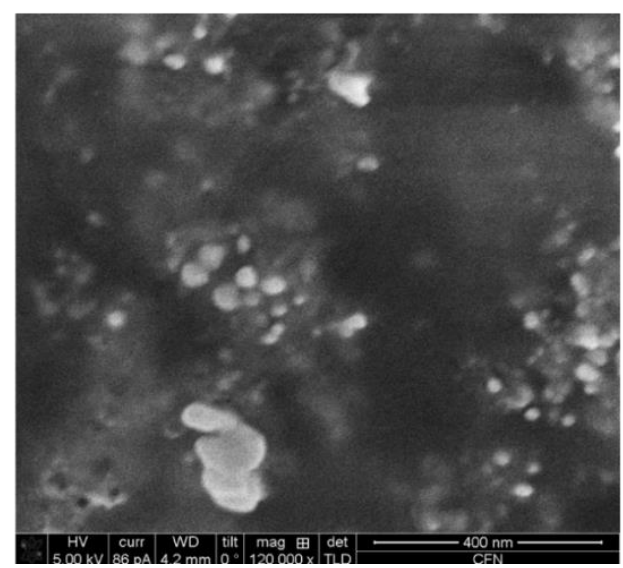

B

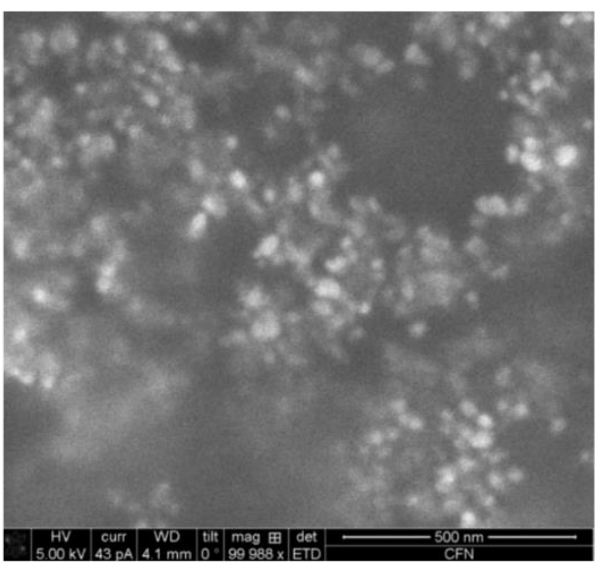

Figure 7. Dual-beam focus ion beam (FIB) SEM scanning of silver NPs. (A): NPs synthesized by pUC19-Vec cells under SEM; (B): NPs synthesized by pUC-Met cells.

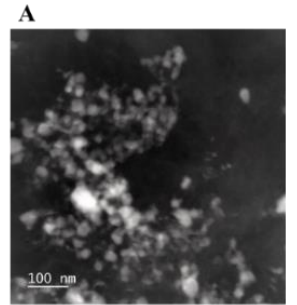

pUC19-Vec

F



C

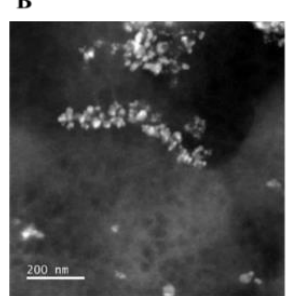

pUC19-Vec

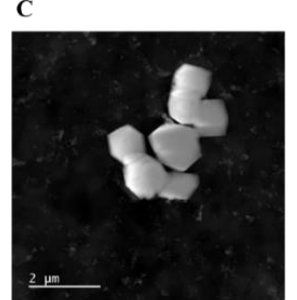

pUC19-Vec

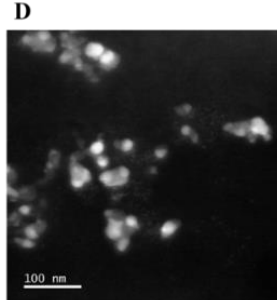

pUC-Met

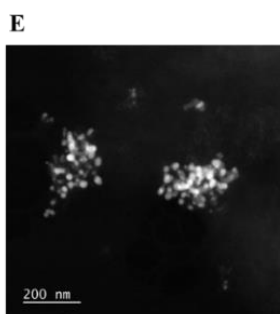

pUC-Met

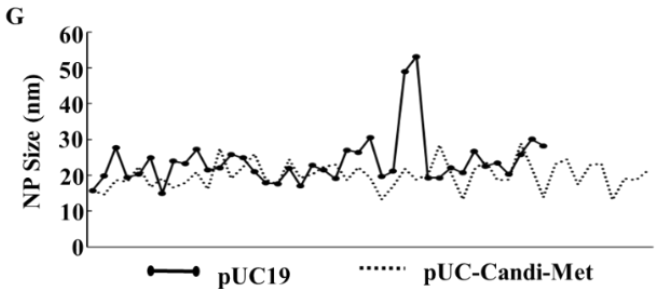

Figure 8. STEM analysis of NPs. (A,B): NPs formed by pUC19-Vec cells. (C). Large silver crystals synthesized by pUC19-Vec cells; (D,E): NPs formed by pUC-Met; $(\mathbf{F})$ : Bar graph showing the size of the NPs determined by STEM. The diameter or the longest side of isolated NPs was analyzed using Gatan Digital Micrograph Software; (G): The distribution of the size of the NPs synthesized by bacteria pUC19-Vec or pUC-Met. N $=40$ NPs in pUC19-Vec; $\mathrm{n}=49$ NPs in pUC-Met. *: $p<0.001$.

\section{Discussion}

Both wild type E. coli and engineered $E$. coli have been shown to be able to synthesize diverse NPs [9-11]; however, it is not clear whether the engineered E. coli cells perform better than non-engineered cells, and whether these cells have the potential to upgrade to large scale NP production. In this study, we explored the potential of application of E. coli DH5 $\alpha$ cells transformed with C. albicans MT gene in the biosynthesis of more uniform silver NPs at lager scale. We used the E. coli DH5 $\alpha$ cells transformed with pUC19 empty plasmid vector as a control, since the $C$. albicans MT gene was delivered into the cells by vector $\mathrm{pUC19}$. Many studies have shown that MT is protective when cells are exposed to metal ions $[6,17,18]$. MT proteins have high binding-affinity for heavy metal ions and serve as important reducing agents under heavy metal stress; thus, MT proteins are critical for proper accumulation, distribution and detoxification of the metal ions $[5,17,18]$. Similarly, our results also showed that the E. coli cells expressing C. albicans MT (pUC-Met cells) tolerated $\mathrm{CuSO}_{4}$ challenge better than the pUC19-Vec cells. During the prolonged cultivation in the absence of metal ion stress, the $\mathrm{OD}_{600 \mathrm{~nm}}$ of pUC-Met cells was higher than that of pUC19-Vec cells at 24, 48 and $72 \mathrm{~h}$ after the $\mathrm{OD}_{600 \mathrm{~nm}}$ reached 0.6-0.8 (Figure 3A). Importantly, when the cells were subjected to copper 
ion stress for 17-19 h, the pUC-Met cells grew to a significantly higher OD $_{600 \mathrm{~nm}}$ than the pUC19-Vec cells (Figure 3B). In particular, assessment of cell viability confirmed that pUC-Met cells had a higher survival rate than pUC19-Vec cells after bacteria were exposed to heavy metal stress (Figure 3C). The better growth and higher survival of bacteria under heavy metal challenge suggested that the pUC-Met cells had increased tolerance to the metal ions, presumably due to the expression of C. albicans MT protein. C. albicans MT has a relatively high content of cysteine residues that can be used to reduce silver ions, bind and accumulates silver particles in the cells, thus, protect the cells from the toxicity of silver ions. We proposed that the higher tolerance to metal ions would subsequently promote the cells to make more NPs if they are used as biofactories for metal NP synthesis. Indeed, when the cells were grown in the presence of $1 \mathrm{mM} \mathrm{AgNO}$, the pUC-Met cells consistently produced more silver NPs at each examination time point (Figure 4A-E), and the final yield of NPs from 1liter culture by pUC-Met cells was greater than that of the pUC19-Vec cells (Figure $4 \mathrm{E}, 1 \mathrm{~g} / \mathrm{L} \mathrm{vs.} 0.74 \mathrm{~g} / \mathrm{L}$ ). The yield of a wet pellet of bacterial culture in the presence of $1 \mathrm{mM} \mathrm{AgNO}_{3}$ for $72 \mathrm{~h}$ was not compromised by increasing culture medium volume from $0.1 \mathrm{~L}$ to $1 \mathrm{~L}$, suggesting that upgrade to large scale NP production is very promising, although more experiments are needed to confirm the conclusion. Thus, our results demonstrated that expression of $C$. albicans $\mathrm{MT}$ in $E$. coli promoted cell growth and survival and enhanced biosynthesis of silver NPs in these cells.

Even if the mechanisms of bacterial synthesis of metallic NPs remain to be completely elucidated, it has been postulated that the presence of reducing groups that can donate electrons to metal ions, such as phenol, amide, thiols and other unsaturated bonds, of the organic matter in bacteria play an important role in reducing and binding metal ions $[12,25]$. To shed light into the mechanisms of bacterial NP synthesis, we analyzed the reducing functional groups using FTIR. FTIR identified compounds that probably contain phenol, amines, amide I and isothiocyanate functional groups in all cells (Figure 5). We hypothesized that the oxidization of $\mathrm{C}-\mathrm{OH}$ group in organic molecules to $\mathrm{C}=\mathrm{O}$ (amide I) group probably was involved in the reduction of $\mathrm{Ag}^{+}$ions to $\mathrm{Ag}^{0}$. In addition, the amide I groups may cap and stabilize the silver NPs once the $\mathrm{Ag}^{+}$ions were converted into $\mathrm{Ag}^{0}$. The possible amines $(\mathrm{N}-\mathrm{H})$ of biomolecules, such as proteins, may as well act as binding and stabilizing agents of silver NPs. Furthermore, it is well accepted that the O-H stretching in alcohols and phenolic compounds are used to reduce the $\mathrm{Ag}^{+}$ions into $\mathrm{Ag}^{0}$ in the biological synthesis of metal NPs [22-24]. Therefore, the FTIR analysis suggested that the bacteria in our study probably used similar reducing agents to reduce $\mathrm{Ag}^{+}$ions to $\mathrm{Ag}^{0}$ as reported [12,22-25]. Interestingly, a possible isothiocyanate $(\mathrm{N}=\mathrm{C}=\mathrm{S})$ was observed in the bacteria synthesized silver NPs. Isothiocyanates are sulfur-containing antioxidants that have antimicrobial activities [26]. It is true that the strong reducing agent isothiocyanates can play a role in biosynthesis of silver NPs, it is yet to elucidate how and why the engineered bacteria produced these compounds that can kill themselves.

We expected that the FTIR could detect thiol groups, since the cysteine residues in the MTs contain thiol groups. However, FTIR could not catch the thiol groups associated with silver. We speculate that the thiol group, which usually is assigned to a weak peak around $2600 \mathrm{~cm}^{-1}$, might be buried in the stretches of the strong peaks adjacent to $2600 \mathrm{~cm}^{-1}$. To complement this drawback of FTIR, compositions of silver NPs were further assessed by STEM and SEM. Importantly, the compositional analysis confirmed that silver atoms were among the key elements in the NPs. Further, consistent with our prediction, sulfur atoms were indeed detected associated with these silver NPs, indicating that the thiol groups of proteins were involved in reducing silver ions and accumulating silver NPs (Figure 6). Therefore, our results not only confirmed that the NPs were indeed silver NPs, but also supported that thiol groups were involved in reducing and binding silver NPs. Since C. albicans MT has a higher level of cysteine residues that can generate a higher reducing power and metal-binding affinity in pUC-Met cells than the pUC-Met cells, we believe that the expression of $C$. albicans MT in E. coli cells allowed the cells to convert more silver ions, and faster into silver NPs, and therefore, protected the cells from silver ion stress, as well as increased the bacterial NP yield. 
Another finding of the SEM compositional assessment was the detection of chloride and copper associated with silver NPs. It has been shown that chloride is one of the key elements that $E$. coli use to counter silver NP toxicity [27]. The identification of chloride associated with silver NPs suggested that the E. coli not only used thiol groups, but also chloride to reduce and accumulate silver under silver ion stress. It is not surprising that copper was also detected in the NPs, since C. albicans MT was originally discovered as a copper-binding protein, and its expression was induced by copper ions [17,18].

FTIR analysis, SEM and STEM examinations obtained similar results in the NPs synthesized by pUC19-Vec and pUC-Met cells, suggesting the two groups of cells probably used similar mechanisms to reduce silver ions and produce NPs. However, the expression of C. albicans MT protein in E. coli conferred the engineered recombinant cells higher tolerance and better survival, thus, greater capacity to synthesize silver NPs when exposed to silver ions.

One of the problems associated with biologically synthesized NPs has been morphological heterogeneity of the NPs [12-14]. A primary goal of this study was to investigate whether engineered E. coli cells can improve the quality of NPs. Both SEM and STEM demonstrated that the two groups of $E$. coli cells successfully produced silver particles in the nano-size range. The average size of NPs synthesized by pUC-Met cells is slightly, but significantly, smaller than the size of those produced by pUC19-Vec cells (Figure 8F,G). However, there was a greater variation in the sizes of the NPs synthesized by pUC19-Vec cells (SD: $3.7 \mathrm{~nm}$ in pUC-Met vs. $7.3 \mathrm{~nm}$ in pUC19-Vec). Note that calculation of this SD did not include the large crystals mentioned below). Surprisingly, some micro-size silver crystals were formed by these cells (Figure 8C). Overall, our data showed that NPs produced by pUC-Met cells not only had a more uniform size, but also appeared to have a more uniform shape. As shown in Figure 7B, Figure 8D,E, under SEM and STEM, it appeared that the NPs made by pUC-Met cells had a round shape, while the morphology of NPs from pUC19-Vec cells was more heterogeneous, which showed round, rectangular prism and hexagonal prism shapes (Figures 7A and 8A,C). Thus, we demonstrated that both pUC19-Vec and pUC-Met bacterial groups were able to synthesize silver NPs. Nevertheless, the bacteria expressing C. albicans MT had a better control in the dimension and morphology of silver NPs and a higher yield of NPs. The mechanisms of how the pUC-Met recombinant bacteria synthesized NPs with a more uniform size and shape remains to be elucidated. We speculate that more thiol groups in pUC-Met cells have a higher reducing power and a greater binding capacity for silver ions, which probably allows the cells to produce NP faster; meantime, more thiol groups can provide a larger silver binding capacity, which is more potent to stabilize the silver NPs once the silver ions are reduced. Faster reducing reactions along with a higher capacity to stabilize the NPs probably allowed the cells to synthesize NPs with a smaller size and higher uniformity.

\section{Conclusions}

In summary, we revealed that the expression of C. albicans MT in E. coli cells allowed these cells to biologically synthesize more silver NPs at a higher yield. An important finding is that these engineered recombinant $E$. coli cells appeared to have better control in the size and shape of the NPs. Moreover, the procedures used to grow, propagate the engineered bacteria, as well as the methods used to produce silver NPs, in our study, are quite simple and easy to set up in any microbiology laboratories. Expansion of this engineered E. coli as a platform for the biosynthesis of other metal NPs, optimization of bacterial growth conditions to upgrade the method for large scale production of uniform metal NPs, as well as an exploration of the potential of in vitro NP synthesis by these engineered cells will be among our goals in the future. The results of this study provided preliminary information for genetically modifying bacteria as promising biofactories for large-scale production of size- and shape-controlled NPs for their applications in nanotechnology.

Author Contributions: Q.Y. designed the experiments, synthesized genes, produced the engineered bacteria, produced NPs analyzed the data and wrote the manuscript. Z.X. characterized the NPs, analyzed data and contributed to writing the manuscript. M.B. did FTIR to analyze the functional groups in NP samples and reviewed the manuscript. 
Funding: This study was supported by funding from DoD/ARO (award number: W911NF1810444).

Acknowledgments: The research is supported by DoD/ARO under Grant No. W911NF-18-1-0444. Research carried out in part at the Center for Functional Nanomaterials, Brookhaven National Laboratory, which is supported by the U.S. Department of Energy, Office of Basic Energy Sciences, under Contract No. DE-SC00112704. The authors greatly appreciate: Ms. Shonda Scott at the Chemistry Program at Alabama A\&M University for her help in FTIR analysis; Yong Ding at George Institute of Technology for his help in performing the TEM analysis; and Fernando Camino at Brookhaven National Laboratory for his help in obtaining the SEM pictures.

Conflicts of Interest: The authors declared no conflict of interest.

\section{References}

1. Tiquia-Arashiro, S.; Rodrigues, D. Extremophiles: Applications in Nanotechnology; Springer: New York, NY, USA, 2016; pp. 163-193.

2. Iravani, S.; Korbekandi, H.; Mirmohammadi, S.V.; Zolfaghari, B. Synthesis of silver nanoparticles: Chemical, physical and biological methods. Res. Pharm. Sci. 2014, 9, 385-406. [PubMed]

3. Lloyd, J.R. Microbial reduction of metals and radionuclides. FEMS Microbiol. Rev. 2003, 27, 411-425. [CrossRef]

4. Singh, P.; Kim, Y.J.; Zhang, D.; Yang, D.C. Biological synthesis of nanoparticles from plants and microorganisms. Trends Biotechnol. 2016, 34, 588-599. [CrossRef] [PubMed]

5. Calvo, J.; Jung, H.; Meloni, G. Copper metallothioneins. Int. Union Biochem. Mol. Biol. 2017, 69, $236-245$. [CrossRef] [PubMed]

6. Reddy, M.S.; Prasanna, L.; Marmeisse, R.; Fraissinet-Tachet, L. Differential expression of metallothioneins in response to heavy metals and their involvement in metal tolerance in the symbiotic basidiomycete Laccaria bicolor. Microbiology 2014, 160, 2235-2242. [CrossRef] [PubMed]

7. Park, T.J.; Lee, K.G.; Lee, S.Y. Advances in microbial biosynthesis of metal nanoparticles. Appl. Microbiol. Biotechnol. 2016, 100, 521-534. [CrossRef]

8. Rubino, F.M. Toxicity of glutathione-binding metals: A review of targets and mechanisms. Toxics 2015, 3, 20-62. [CrossRef]

9. Kang, S.H.; Bozhilov, K.N.; Myung, N.V.; Mulchandani, A.; Chen, W. Microbial synthesis of Cds nanocrystals in genetically engineered E. coli. Angew. Chem. Int. Ed. 2008, 47, 5186-5189. [CrossRef]

10. Park, T.J.; Lee, S.Y.; Heo, N.S. In vivo synthesis of diverse metal nanoparticles by recombinant Escherichia coli. Angew. Chem. Int. Ed. Engl. 2010, 49, 7019-7024. [CrossRef]

11. Choia, Y.; Park, T.J.; Lee, D.C.; Lee, S.Y. Recombinant Escherichia coli as a biofactory for various single- and multi-element nanomaterials. Proc. Natl. Acad. Sci. USA 2018, 115, 5944-5949. [CrossRef]

12. Ghashghaei, S.; Emtiazi, G. The methods of nanoparticle synthesis using bacteria as biological nanofactories, their mechanisms and major applications. Current Bionanotechnol. 2015, 1, 3-17. [CrossRef]

13. Ovais, M.; Khalil, A.T.; Ayaz, M.; Ahmad, I.; Nethi, S.K.; Mukherjee, S. Biosynthesis of metal nanoparticles via microbial enzymes: A mechanistic approach. Int. J. Mol. Sci. 2018, 19, 4100. [CrossRef] [PubMed]

14. Kushwaha, A.; Singh, V.K.; Bhartariya, J.; Singh, P.; Yasmeen, K. Isolation and identification of E. coli bacteria for the synthesis of silver nanoparticles: Characterization of the particles and study of antibacterial activity. Eur. J. Exp. Biol. 2015, 5, 65-70.

15. Vijayanandan, A.S.; Balakrishnan, R.M. Biosynthesis of cobalt oxide nanoparticles using endophytic fungus Aspergillus nidulans. J. Environ. Manag. 2018, 218, 442-450. [CrossRef] [PubMed]

16. Patel, V.; Berthold, D.; Puranik, P.; Gantar, M. Screening of cyanobacteria and microalgae for their ability to synthesize silver nanoparticles with antibacterial activity. Biotechnol. Rep. 2015, 5, 112-119. [CrossRef]

17. Oh, K.B.; Watanabe, T.; Matsuoka, H. A novel copper-binding protein with characteristics of a metallothionein from a clinical isolate of Candida albicans. Microbiology 1999, 145, 2423-2429. [CrossRef]

18. Xu, X.; Duan, L.; Yu, J.; Su, C.; Li, J.; Chen, D.; Zhang, X.; Song, H.; Pan, Y. Characterization analysis and heavy metal-binding properties of CsMTL3 in Escherichia coli. FEBS Open Bio 2018, 8, 1820-1829. [CrossRef]

19. Marsic, D.; Hughes, R.C.; Byrne-Steele, M.L.; Ng, J.D. PCR-based gene synthesis to produce recombinant proteins for crystallization. BMC Biotechnol. 2008, 8, 44. [CrossRef]

20. Ali, J.; Ali, N.; Wang, L.; Waseem, H.; Pan, G. Revisiting the mechanistic pathways for bacterial mediated synthesis of noble metal nanoparticles. J. Microbiol. Meth. 2019, 159, 18-25. [CrossRef] 
21. Hun, S.H.; Jun, B.H. Silver nanoparticles: Synthesis and application for nanomedicine. Int. J. Mol. Sci. 2019, 20, 865-888.

22. Ramesh, A.; Sundari, M.T.; Thirugnanam, P.E. Microbial Molecular Mechanisms in Biosynthesis of Nanoparticles. In Bio-Nanoparticles: Biosynthesis and Sustainable Biotechnological Implications; Singh, O.V., Ed.; Wiley: Hoboken, NJ, USA, 2015.

23. Malapermal, V.; Botha, I.; Krishna, S.B.N.; Mbatha, J.N. Enhancing antidiabetic and antimicrobial performance of Ocimum basilicum, and Ocimum sanctum (L.) using silver nanoparticles. Saudi J. Biol. Sci. 2017, 24, 1294-1305. [CrossRef] [PubMed]

24. Singhal, G.; Bhavesh, R.; Kasariya, K.; Sharma, A.R.; Singh, R.P. Biosynthesis of silver nanoparticles using Ocimum sanctum (Tulsi) leaf extract and screening its antimicrobial activity. J. Nanop. Res. 2011, 13, 2981-2988. [CrossRef]

25. Prabhu, S.; Poulose, E.K. Silver nanoparticles: Mechanism of antimicrobial action, synthesis, medical applications, and toxicity effects. Int. Nano Lett. 2012, 2, 32. [CrossRef]

26. Dufour, V.; Stahl, M.; Baysse, C. The antibacterial properties of isothiocyanates. Microbiology 2015, 161, 229-243. [CrossRef]

27. Levard, C.; Mitra, S.; Yang, T.; Jew, A.D.; Badireddy, A.R.; Lowry, G.V.; Brown, G.E. Effects of chloride and ionic strength on physical morphology, dissolution, and bacterial toxicity of silver nanoparticles. Environ. Sci. Technol. 2013, 47, 5738-5745. [CrossRef]

(C) 2019 by the authors. Licensee MDPI, Basel, Switzerland. This article is an open access article distributed under the terms and conditions of the Creative Commons Attribution (CC BY) license (http://creativecommons.org/licenses/by/4.0/). 